secretaries to the newly appointed Associate Editors and maintained, it seems, to the present.

The Associate Editors were the key to the next stage in the growing up of Thorax. Dividing up the workload had become a practical necessity given the volume of time consuming work, but what resulted was teamwork which improved the standard and broadened the character of the journal as well as providing stimulating companionship.

Jumping ahead two decades, we find Thorax promoted to a higher league having emerged from its domestic embrace to be resoundingly adopted by the international respiratory community as a whole. Quality undoubtedly attracts quality, but this virtuous positive feedback is not an automatic process. The combination of energy, imagination, and care contributed by the recent Editors has been the essential catalyst and great credit is due to them. Editing is often described as a thankless task. This may not be strictly true, but it is very nearly so. Few letters of thanks are to be found pinned to the Editor's wall (or, nowadays, perhaps un-erased in the inbox). In celebrating the 60th anniversary of Thorax there is an opportunity to thank the Editors of recent years for their part in the evolution of a journal in which all involved in thoracic medicine and its related sciences can take some pride.

Congratulations Thorax; thank you recent Editors; keep going ...

Editor, 1982-1987

Thorax 2006;61:1018-1019.

doi: $10.1136 /$ thx.2006.072702

Correspondence to: $\operatorname{Dr} R$ A L Brewis, High Barn, High Side, Bassenthwaite, Keswick, Cumbria CA12 4QG; alistairbrewis@btinternet.com

\title{
Thorax at 60
}

\section{A E Tattersfield}

$\mathrm{E}$ ditors look for articles that say something new, and studies don't have to be large and grand. I have selected two papers and an editorial from among the many I could have chosen. They may not be landmark articles, but they are probably the three articles I have quoted most widely in discussions and teaching. I enjoy the fact that the two studies are simple, showing that valuable information can still be obtained by studying patients carefully and without breaking the bank.

First is a paper by Tweedale et al which looked at short term repeatability of $\mathrm{FEV}_{1}$ and bronchodilator responsiveness in patients with airflow obstruction. The authors showed that within subject differences in $\mathrm{FEV}_{1}$ measurements made 20 minutes apart were usually within $160 \mathrm{ml}$, and that this was true whether the initial FEV 1 was 1 or 5 litres. This has been enormously useful when planning studies and also when interpreting small changes in $\mathrm{FEV}_{1}$ in individual patients. The article also highlighted the difficulty of defining a bronchodilator response-whether to use a percentage change which favours patients with a low $\mathrm{FEV}_{1}$ or an absolute response exceeding $160 \mathrm{ml}$, which favours those with a high $\mathrm{FEV}_{1}$ - to mention just two methods The paper didn't provide the answer but, by relating responses to repeatability, provided a clearer picture of how such data should be interpreted.

Second is an even simpler study, ${ }^{2}$ carried out I think by a medical student, which refuted the classical teaching that detection of cyanosis implies that the patient has $5 \mathrm{~g} / \mathrm{dl}$ reduced haemoglobin. This assertion had been questioned by Flenley among others but was (and still is) repeated by most medical students and some widely used textbooks. In the Thorax paper two observers looked for cyanosis in 80 normothermic patients with a wide range of arterial oxygen tensions. Cyanosis was detected invariably when the reduced haemoglobin concentration approached $1.5 \mathrm{~g} / \mathrm{dl}$, equivalent to an oxygen saturation of around $90 \%$ in patients with a normal haemoglobin concentration. This can be confirmed easily on any ward round Although knowing the correct cut off may be less important now that oximeters are widely available, understanding the physiological basis of clinical signs is important for sensible interpretation and management. A further point is whether students will be penalised if they give the correct answer, since many teachers and presumably examiners still appear to believe that the cut off is $5 \mathrm{~g} / \mathrm{dl}$. If they are, please refer the examiner to this paper.
And finally-the editorial ${ }^{3}$ in which McNeil, Sveger and Thelin discussed the psychosocial effects of neonatal screening for somatic mutations, based on screen-

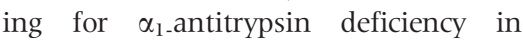
Sweden in the 1970s. It may seem obvious that parents who were told that their child had $\alpha_{1}$-antitrypsin deficiency would take extra precautions to ensure that the child was brought up in a smoke free environment. Not so, however. Follow up studies showed that the stress induced by receiving information about a "potential disease" had the opposite effect, with at least one parent smoking in over half the homes (and twice as many fathers smoked compared with a control group) and the children showed more behavioural problems. The 1970s were early days for understanding the natural history of $\alpha_{1}$-antitrypsin deficiency, for genetic counselling, and for the public's understanding of genetics, and all would be very different today. The message, however, that the effects of counselling need to be tested and cannot necessarily be assumed, is still valid. Editor, 1987-1991

Thorax 2006;61:1019.

doi: $10.1136 /$ thx. 2006.072686

Correspondence to: Professor A E Tattersfield, Division of Respiratory Medicine, Clinical Sciences Building, Nottingham University Hospital, City Hospital Campus, Nottingham NG5 1PB, UK; anne.tattersfield@nottingham. ac.uk

\section{REFERENCES}

1 Tweedale PM, Alexander F, McHardy GJR. Short term variability in $\mathrm{FEV}_{1}$ and bronchodilator responsiveness in patients with obstructive ventilatory defects. Thorax 1987:42:487-90.

2 Goss GA, Hayes JA, Burdon JGW. Deoxyhaemoglobin concentrations in the detection of cyanosis. Thorax 1988;43:212-3.

3 McNeil TF, Sveger T, Thelin T. Psychosocial effects of screening for somatic risk: the Swedish alpha 1 antitrypsin experience. Thorax 1988;43:505-7 